\title{
O caminho da mudança: fatores-chave para a nova etapa nos Mercados Globais de Informação e Comunicação
}

The path to change: key factors to the new stage of Global Information and Communication Markets

Submetido(submitted): 16 de setembro de 2009

Parecer(revised): 20 de outubro de 2009

Aceito(accepted): 13 de novembro de 2009

Renata Tonicelli de Mello Quelho*

RESENHA DO LIVRO:

Peter F. Cowhey and Jonathan D. Aronson, with Donald Abelson. Transforming Global Information and Communication Markets: The Political Economy of Innovation. Cambridge: MIT Press, 2009, 341p. $(\mathrm{R} \$ 82,62){ }^{* *}$

O objeto do livro é simples: tratar do maior projeto da história da humanidade, que exigiu mais recursos e esforços do que a construção da muralha da China e do que as pirâmides do Egito. ${ }^{1}$ É um projeto que exige ação a nível global, e que tem como característica o fato de ser indeclinavelmente político: consiste precisamente na infraestrutura de Tecnologia da Informação e Comunicações (TIC) (Information and Communications Technology (ICT) infrastructure).

Os autores partem da premissa de que é falsa a idéia de que o desenvolvimento da tecnologia encontra um caminho de progresso por si só. A marcha tecnológica não foi inevitável; há muitas batalhas políticas que modelaram os caminhos do mercado e que se fazem presentes por meio de novas dinâmicas. O livro mostra a gama de fatores que contribuíram para alcance do estágio que demanda mudanças na economia política das TICs. O que causa essa necessidade de mudanças? Qual é a nova etapa? Quais os

\footnotetext{
*Pesquisadora do Grupo de Estudos em Direito das Telecomunicações da UnB. Bacharela em Direito pela Universidade de Brasília.

${ }^{* *} O$ inteiro teor do livro encontra-se disponível gratuitamente online em http://globalinfoandtelecom.org/.

1"The networked information infrastructure that blends computing and communications is the largest construction project in human history. The money and the effort required to build this infrastructure dwarf what was needed to erect the pyramids of Egypt or the Great Wall of China." (p. 7).

Revista de Direito, Estado e Telecomunicações, v. 2, n. 1, p. 197-212 (2010) 
caminhos trilhados e quais as tendências? Os autores dedicam três capítulos a estudo de casos, em que aplicam as respostas a essas perguntas: às regras de comércio, à economia política de redes sem fio e à governança da Internet.

O ponto de inflexão ${ }^{2}$ é o fio condutor da pesquisa e surge diante do contexto de que todos os componentes de infraestrutura estão se tornando modulares. Cowhey e Aronson remetem ao conceito de modularidade (modularity) $)^{3}$. Tal conceito reside na metáfora da Lego construindo blocos de muitas formas que podem ser facilmente misturadas e dispostas porque elas têm interfaces padronizadas para se conectarem.

Duas consequências surgem da modularidade. Primeiramente, o ponto de inflexão muda significativamente as oportunidades de competição na indústria de TIC. A modularização permite convergência mais ampla dentro de capacidades funcionais. Ela diminui os custos de desenvolvimento e permite um desenvolvimento mais rápido. Como resultado, a competição tem tomado todas as frentes. Em segundo lugar, o ponto de inflexão rompe a TIC fora dos compartimentos geográficos e funcionais, abrindo novas fronteiras para aplicações.

Tendo em vista que os Estados Unidos dominam o segmento do mercado e as inovações tecnológicas que conduzem ao ponto de inflexão, os autores apresentam a idéia de que esse país tem papel central nos mercados globais de TIC por três características institucionais importantes: divisão de poderes, sistema eleitoral majoritário e federalismo (p. 26-29).

Cowhey e Aronson argumentam que até 2025 os Estados Unidos poderão liderar ${ }^{4}$, mas não ditar, as escolhas mundiais sobre as políticas futuras. Desde a $2^{\mathrm{a}}$ Guerra Mundial, os Estados Unidos - o ator econômico mais poderoso - usualmente desempenharam o papel de líderes na história

\footnotetext{
${ }^{2}$ Referência ao former Intel chairman Andy Grove: "Um ponto de inflexão ocorre quando o quadro da velha estratégia se dissolve e dá lugar à nova" (p. 7). Matematicamente, é o ponto onde muda a curvatura de uma função.

${ }^{3}$ Referência a Farrell and Weiser, "Modularity, vertical integration and open access policies: Towards a convergence of antitrust and regulation in the Internet age", Harvard Journal of Law and Technology 17 (2003), n. 1: 85, 100-105. Notes to chapter 3. (p. 278).

${ }^{4}$ Os autores oferecem cinco premissas para que os Estados Unidos continuem o pivô do ponto de inflexão e dominem a política econômica de TIC até 2025 (p. 95).

Revista de Direito, Estado e Telecomunicações, v. 2, n. 1, p. 197-212 (2010)

DOI: https://doi.org/10.26512/lstr.v2i1.21688
} 
da transformação global. As novas escolhas políticas dispostas pelo ponto de inflexão ocorrerão enquanto os Estados Unidos continuarem como o pivô político, econômico, e tecnológico do mercado mundial.

A obra explicita que o desafio principal é criar novos espaços apropriados para competição de mercado que permita o potencial para inovação de modo que melhore o bem-estar do consumidor. Essa explicação se fundamenta na análise do ponto de inflexão na fronteira tecnológica que forçará aqueles com interesses comerciais e aqueles que analisam a política de TIC a reconsiderar presunções antigas e compromissos políticos.

No capítulo 2, é apresentada explicação dos fatores tecnológicos, políticos e econômicos que levaram a mudanças no mercado norteamericano de 1950 até 2000.

Os autores distinguem dois períodos da infraestrutura da tecnologia da informação e comunicação desde 1950: o primeiro ocorreu durante os anos que se seguiram ao pós-guerra e se estendeu até o desmembramento da AT\&T, e o segundo, entre 1984 até 2000.

Do estudo, dois elementos da política se destacaram na análise desses períodos: a indústria de TIC se tornou mais modular desde 1950 e, paralelamente, governos adotaram políticas pró-competição. Eles se utilizaram de políticas intervencionistas que promoveram infraestruturas competitivas que melhoraram a competição de serviços e pressionaram os competidores a adotar a modularidade.

No momento atual, a modularidade e a competição crescente trazem uma série de revoluções que alteram não só o âmbito tecnológico, mas também as estratégias de mercado e políticas.

Nesse sentido, a obra destaca três implicações cruciais de primeira ordem na modularidade. Primeiro, ela facilitou a Revolução a Baixos Custos (Cheap Revolution $)^{5}$; segundo, permitiu mais eficiência, rapidez e

${ }^{5}$ Uma implicação direta da modularidade é a Cheap Revolution, isto é, o barateamento de itens de TIC em vários segmentos do mercado. A revolução na microeletrônica confere maior poder aos terminais, enquanto que nos softwares indica que 'aplicações podem ser executadas em qualquer lugar'. A revolução nas redes impulsiona as Next-Generation Networks. A lógica da modularidade está se movendo além do hardware, software e dados e alcança até mesmo os conteúdos de mídia. 
barateamento do acoplamento dos blocos de TIC; terceiro, com banda larga ubíqua, ${ }^{6}$ permitirá estender aplicações de informação interligadas em rede para além dos centros acadêmicos e centros tradicionais de negócios. Um efeito cumulativo da modularidade é a aceleração do crescimento da importância de plataformas multidimensionais (multi-sided plataforms) que alteram a dinâmica de preços e de competição de um modo que não é encontrado na maioria dos ambientes não digitais. Esse tipo de plataforma serve a vários tipos de consumidores que são mutuamente dependentes e cuja participação torna a plataforma valiosa para cada um. ${ }^{7}$

Para explicar o próximo passo nas infraestruturas de tecnologia da informação e comunicações, é apresentada a metáfora da indústria da moda, visto que essa metáfora proporciona um meio para compreender como a modularidade pode abrir novos padrões de inovação e redefinir mercados.

Trata-se de uma metáfora imperfeita, mas que captura dinâmicas essenciais para a modularidade. No lado do fornecimento, a indústria da moda é caracterizada por complexas e desagregadas cadeias globais de fornecimento, onde produção, distribuição e design são conectados por redes globais. Essas redes possuem especialistas flexíveis que contribuem por módulos (p.ex. textura, corte, botões, couro, dentre outros) e que podem se adequar às necessidades sazonais em 'um produto verticalmente integrado' (p. ex. um terno). Alguns especialistas têm escala e possuem capital significativo, mas muitos outros têm menor escala e enfatizam habilidades especializadas. Também há um elemento no qual o destino de vendedores específicos ergue-se e cai de temporada para temporada baseado na procura contínua por produtos de sucesso (hit products). A indústria da moda detém impacto mínimo de componentes singulares (tecido, botão), mas significância de escala econômica na distribuição, produção e design.

Para ilustrar o potencial da metáfora da indústria da moda, os autores discorrem a respeito do iPod e do mercado de terminais. Ambos dependem de canais de entrada especializados, mas integram tudo em torno de um produto da moda (fashion) com conceito e qualidade. $\mathrm{O}$ aspecto mais

\footnotetext{
${ }^{6}$ No sentido de estar sempre disponível e conectada.

${ }^{7}$ Como exemplo tem-se que o Windows é um mercado de três lados porque a plataforma de software é profundamente interdependente dos desenvolvedores de aplicativos, usuários finais e produtores de hardware.
}

Revista de Direito, Estado e Telecomunicações, v. 2, n. 1, p. 197-212 (2010)

DOI: https://doi.org/10.26512/1str.v2i1.21688 
lucrativo do pacote do iPod é o dispositivo em si (hardware). Isso esclarece os limites em destacar um elemento na cadeia de valores - o terminal -, em segmentos adjacentes do mercado - conteúdo digital. ${ }^{8}$

Por que a governança (governance) de mercado muda em certas direções? O que provoca essa mudança? Os autores adotam uma teoria que tem por enfoque as forças que governam o mercado que atuam em dois lados da equação: o lado impulsionado por mudanças tecnológicas e o lado que é dependente da estrutura da tomada de decisão e delegação de poder a determinadas instituições (demand side e supply side of the equation) (p. 134).

A tecnologia desempenha o papel de forçar as escolhas dos players nos mercados globais. Ela aumenta a possibilidade de mudança, mas não dita uma alteração em específico. Ela, finalmente, busca equilibrar interesses e estratégias, criando oportunidades e riscos, desafiando o modelo predominante do mercado.

Por sua vez, escolhas feitas por acordos ou instituições formais ou informais sobre o desenho da governança do mercado influenciam os direitos de propriedade, a eficiência técnica, o caminho da inovação global, e quem ganha e perde na arena global. Uma escolha significativa na governança do mercado é a decisão sobre que poderes delegar para quais organizações formais (internacionais) ou informais (ONGs) porque a escolha do agente implica uma agenda para futura negociação e ação. A alteração da governança global pode demandar a mudança da instituição que a lidera.

Nesse sentido, os países mais poderosos no cenário mundial têm a função de difundir e estabelecer a agenda política da mudança de governança. ${ }^{9}$ Eles controlam não só a negociação, como também os recursos

${ }^{8} \mathrm{Há}$ três elementos da metáfora fashion que podem ser perfeitamente ilustradas pelo iPod. Primeiro, o ciclo de vida de um produto é curto. Segundo, o iPod pressupõe um componente de serviços em nuvem (cloud) para complementar o terminal (música, conteúdo), permitindo rápida inovação e escolhas entre quais as formas e funções que o terminal assume. Por último, o iPod revela o complexo terreno competitivo criado pela presença de uma sofisticada cadeia de fornecimento e a convergência de competidores de várias partes e segmentos em um mercado único.

${ }^{9}$ A governança de mercado pode contribuir para facilitar a transação, tomada de decisão e implementação de acordos formais ou informais entre atores internacionais. Um segundo papel da governança é o de estabelecer e administrar 
que asseguram a implementação, podendo exercer coerção, incentivos, ou utilizar diplomacia e também o que seria um poder de agenda negativo, que impede maiores alterações no status quo.

Cowhey e Aronson buscam entender a esfera de mudanças possíveis para desenvolver um retrato realista de alternativas por meio do estudo de três casos: regras de comércio; wireless; e internet.

O capítulo 7 apresenta como a alteração das regras de comércio, a revolução global das redes e as mudanças tecnológicas foram catalisadores que levaram à transformação de políticas do mercado interno nas duas primeiras eras de TIC.

Inicialmente, as regras de comércio não tinham jurisdição sobre serviços de comunicação e informação, mas a crescente competição de valor adicionado resultou no Agreement on Basic Telecommunications Services negociado na Organização Mundial do Comércio em 1997.

A entrada da OMC no tema dos serviços de mercados TIC alterou três características da governança de mercado global. Primeiro, os maiores centros do mercado delegaram poder significativo sobre os arranjos de competição para comunicações globais a OMC em detrimento da União Internacional de Telecomunicações (UIT). Isso alterou a agenda e a expertise, governando o mercado internacional de comunicações. Segundo, as regras da OMC, especialmente no acordo de 1997, alteraram as regras de competição e direitos de propriedade no mercado, mudando assim a eficiência e os ganhadores e perdedores nos mercados globais. Terceiro, as primeiras duas mudanças alteraram a composição da comunidade de especialistas influenciando a governança global. Descobrir como racionalizar e administrar um monopólio natural não era mais a ideia central. Em vez disso, demonstrar expertise em administrar a política de competição e regras de comércio se tornaram essenciais. A nova pergunta que surgiu foi: "Qual é o melhor caminho para fazer proveito da competição para incrementar o bem-estar do consumidor ao mesmo tempo em que se mantém um forte arcabouço regulatório como guia?” (p. 149).

regras nas coordenações técnicas e na competição de mercado. Em um terceiro papel, a governança pode permitir que vários atores e grupos de interesse criem capacidades coletivas, incluindo o fornecimento de serviços globais, como a Intelsat.

Revista de Direito, Estado e Telecomunicações, v. 2, n. 1, p. 197-212 (2010)

DOI: https://doi.org/10.26512/1str.v2i1.21688 
$\mathrm{O}$ estudo constata que o acordo da OMC ajudou os maiores mercados industrializados a encontrarem uma maneira mais eficiente para abrir mercados a investimentos estrangeiros e a interligação de redes internacionais. $\mathrm{O}$ advento da OMC também forneceu um sinal para a UIT de que não seria mais tolerado o seu antagonismo a competição e a reformas de comércio.

Cowhey e Aronson verificam que privatização combinada com competição tem incrementado investimentos, diminuído preços, e melhorado a conectividade em países em desenvolvimento, e acreditam que não há razão pela qual a OMC não pudesse revisitar o documento de referência (reference paper) para harmonizar outros princípios políticos que são necessários para alcançar o ponto de inflexão. Em síntese, a harmonização de regulações é uma ferramenta importante para a mudança da governança global.

O capítulo 8 examina a economia política da mudança de governança da infraestrutura sem fio, analisando a introdução dos serviços de banda larga sem fio, tendo em vista que representou uma grande inovação de TIC.

A justificação tradicional para o papel central do governo ${ }^{10}$ encontravase na assertiva de que o espectro de radiofrequência era um recurso público escasso que poderia ser degradado por interferência entre usos que competem entre si. Sob a regulação tradicional de espectro, a mera possibilidade de interferência, e não a sua efetiva interferência, governa quando, onde e que aparelho pode ser usado.

O estudo mostra que esse princípio de controle preventivo de possível interferência é base de uma política restritiva excessiva, e que a idéia de que o espectro é um recurso público escasso controlado pelo governo enfraquece o direito de propriedade e a flexibilidade do mercado.

A obra destaca três normas de política de espectro que permearam a governança doméstica e internacional tradicionais: 1) O espectro era alocado para usos específicos; 2) O número de fornecedores era restringido para proteção contra interferência; 3) Os governos rotineiramente ditavam os padrões técnicos que prevaleceriam. A razão é que um padrão seria a

\footnotetext{
${ }^{10}$ Os governos influenciaram fortemente o processo de inovação no campo das tecnologias sem fio porque controlavam o espectro de radiofrequência, estabeleciam a política de competição e também os padrões técnicos para o mercado.
} 
tecnologia que melhor prevenisse a interferência e também criasse uma economia de escala, diminuindo os custos de equipamento.

Exatamente três desafios diminuíram a força da governança do espectro tradicional: 1) A Revolução a Baixos Custos (Cheap Revolution) transformou a indústria de equipamentos e interligação em rede, bem como a competição nos serviços de telecomunicações; 2) $\mathrm{O}$ incremento da modularidade deu às empresas detentoras de infraestrutura essencial (carriers) mais flexibilidade na mistura de espectro e equipamento para fornecimento de serviços sem fio quando os serviços se tornaram digitais e com banda larga; 3) Os Estados Unidos trouxeram uma visão diferente para os planos do 3G, daqueles feitos pela União Européia (UE) e Japão.

Esse conjunto de fatores forçou a reorganização da delegação de autoridade sobre a governança do mercado global e uma nova abordagem política. Em vez de um único padrão para o $3 \mathrm{G}$, governos aceitaram uma plataforma de padrões relacionados, porém diferentes, e em vez de uma única banda, uma variedade de frequências.

A economia política dos serviços sem fio gerou várias repercussões. Primeiro, os serviços sem fio melhoraram a conectitividade, pois eram mais baratos e rápidos de se lidar do que as redes com fio. O serviço sem fio também forneceu um mercado em crescimento para os monopólios, de modo a compensar as perdas na competição de serviços com fio.

Nessa seção, a obra analisa a tensão entre prestadoras tradicionais (incumbents) e novos entrantes (entrants), enfocando três esferas dos direitos de propriedade: a alocação da capacidade disponível de espectro; a destinação de espectro para licenças específicas; e os padrões técnicos para a rede.

O papel do governo nos mercados de serviço sem fio é produto do enfraquecimento do direito de propriedade, porque se presume que o espectro é um recurso público. Os direitos de propriedade definem as regras do jogo sobre as quais atores econômicos perseguem seus interesses e influenciam a economia dos mercados e as estratégias dos governos e empresas.

O livro aborda o desafio do $3 \mathrm{G}$ e mostra como a introdução da tecnologia de um novo ato setorial (player) ao processo de harmonização dos padrões globais alterou a dinâmica da governança do mercado: a tecnologia CDMA da Qualcomm, que foi selecionada pela Verizon, Sprint, Revista de Direito, Estado e Telecomunicações, v. 2, n. 1, p. 197-212 (2010) 
e outras devido à sua eficiência no uso do espectro. Por sua vez, companhias japonesas e europeias decidiram migrar de GSM para CDMA (ou a variante W-CDMA). Essa decisão criou um grande problema, por causa de uma questão subestimada: uma única companhia americana - a Qualcomm controlava o direito de propriedade intelectual essencial do CDMA. A Qualcomm insistiu em cobrar royalties e desempenhar um papel central no design da arquitetura de $3 \mathrm{G}$ emergente. ${ }^{11}$

Entre as implicações apontadas para a próxima transição em razão dos atrasos dos planos para 3G, destacam-se a alteração de opções tecnológicas, políticas de alocação de espectro, e destinação. Isso altera a interação entre o regime de TIC global e o ponto de inflexão.

$\mathrm{O}$ atraso do $3 \mathrm{G}$ abre mais opções tecnológicas. Por exemplo, o $2.5 \mathrm{G}$ surgiu como uma transição porque poderia ser empregado em redes $2 \mathrm{G}$ como uma melhoria que dispensava a conversão para o $3 \mathrm{G}$. Simultaneamente surgiram novos caminhos para a infraestrutura sem fio, como o WiMAX, com a promessa de ser mais rápido, e mais barato por não ter royalties devidos à Qualcomm. As empresas detentoras de infraestrutura essencial (carriers) se defrontaram com um grande dilema para o $3 \mathrm{G}$ e seus sucessores. O mercado de dados moveu-se para aplicações que exigem maior banda e trouxe a questão de se as empresas detentoras de infraestrutura essencial teriam espectro suficiente com a estrutura de custo delimitada. As grandes carriers, que controlavam a maior parte do mercado sem fio, temiam o declínio de lucros nos serviços de voz, ao mesmo tempo em que pretenderam expandir o crescimento do serviço de dados. Uma ideia era impulsionar a velocidade e a largura de banda (bandwidth) para tornar disponíveis mais aplicações de vídeo. Isso levou ao interesse no híbrido 2.5 ou $3 \mathrm{G} /$ redes $\mathrm{WiFi}$, e estabeleceu a meta de se procurar por tecnologias

\footnotetext{
${ }^{11}$ Fornecedores japoneses e europeus tentaram retirar da Qualcomm a sua posição influente e introduziram o W-CDMA, uma variante do CDMA, que incorporava características do GSM. As grandes empresas detentoras de infraestrutura essencial (carriers) escolheram a versão de $3 \mathrm{G}$ dependendo das suas arquiteturas $2 \mathrm{G}$. As carriers de $2 \mathrm{G}$, em sua maioria europeias e japonesas, optaram por W-CDMA. Aquelas com base CDMA - América do Norte e Coréia - apoiaram a extensão do CDMA para o 3G.
} 
alternativas construídas no WiMAX e em outras companhias bem capitalizadas.

Cowhey e Aronson constatam que, em face dos experimentos americanos com novas formas de políticas de espectro, governos e empresas detentoras de infraestrutura essencial (carriers) viram que os velhos princípios e normas de espectro não exploravam as oportunidades tecnológicas. A exaltação com o WiMAX se voltou para uma controvérsia sobre como definir suas especificações e o espectro para seu emprego. Os mesmos desafios que existiram no $3 \mathrm{G}$ estão levando a variações regionais nos padrões e no espectro. O WiMAX é um novo nome para a tecnologia 802.16. A Coréia está lançando uma tecnologia nacional, a WiBro, no mesmo padrão 802.16e que o WiMAX, criando uma variação sobre o padrão proposto. Em 2007, a UIT reconheceu a família WiMAX como outra parte do portfólio $3 \mathrm{G}$, o que a qualificou para uso de espectro reservado ao 3G em muitos países, mas as bandas de WiMAX ainda variavam.

Os autores constatam que a evolução contínua da competição muda o alinhamento de empresas detentoras de infraestrutura essencial (carriers) e vendedores de equipamentos. A lealdade das carriers aos vendedores de equipamentos importa menos do que a capacidade de reduzir custos. Desde que companhias não possam comprar e vender espectro de forma flexível ou (re)dedicar os serviços livremente num espectro de banda, elas devem combinar o espectro disponível por meio de terminais inteligentes, operando em mais do que frequência e formato tecnológico. O custo da engenharia está diminuindo e provocando uma evolução da interligação em redes. Por exemplo, a televisão nos serviços sem fio está sendo prestada em uma banda diferente da utilizada para dados e voz. Terminais combinam serviços e bandas impecavelmente e são as âncoras para novas aplicações para TIC. De um lado estão os líderes de tecnologia da informação como a Intel, que enxerga um mercado em crescimento e do outro lado, as empresas de telecomunicações, que utilizam suas experiências em terminais, aspirando aos mercados de tecnologia da informação.

A obra destaca que a prioridade da política de competição deveria ser descobrir como permitir que novas alternativas tecnológicas sejam mais facilmente criadas e testadas no mercado. Para esse fim, regras encorajando competição entre empresas detentoras de infraestrutura essencial sem fio (carriers wireless), política de espectro flexível, neutralidade tecnológica, e Revista de Direito, Estado e Telecomunicações, v. 2, n. 1, p. 197-212 (2010) 
alguma liberdade para usuários selecionarem os terminais sem fio e aplicações de software são ferramentas fundamentais para governança. Se a governança do mercado interno se orientar nessa direção, será aberto o espaço para mudanças na governança do mercado global.

No capítulo 9, os autores analisam a questão relevante da internet como indicador de evolução da governança de TIC. A internet ampliou mudanças fundamentais na tecnologia, e seu triunfo comercial foi um produto do contexto específico da economia política dos Estados Unidos.

O capítulo descreve a governança da internet como algo inteiramente novo, que não fora criado puramente pela indústria ou pelo governo, possuindo sua base na comunidade tecnológica que se via de maneira global e não limitada por convenções políticas e ligações com o mercado. Essa perspectiva se refletiu em quatro características da internet: 1) sua arquitetura ignorou limites nacionais; 2) sua coordenação dependeu de comunidades tecnológicas globais que não eram internamente organizadas sobre limites nacionais e representação. As decisões dessa comunidade repousavam em consenso reconhecido por uma autoridade técnica; 3) muitos pontos importantes de coordenação da Internet eram não-lucrativos; 4) atividades de governança se baseavam no correio eletrônico (email), documentação online e outras formas de colaboração interligada em rede, permitida pela internet.

Três princípios guiaram as normas específicas para a governança da internet. Primeiramente, a própria arquitetura da internet exigia que a inteligência fosse colocada no limite da rede, em contraste com as redes tradicionais de telefonia e as redes de dados primárias. A idéia era criar interligação em rede descentralizada e flexível que usaria a capacidade plena da interligação em rede de pacotes digitais. Em segundo lugar, foi decidido que a arquitetura deveria apoiar interoperabilidade genuína entre redes e dispositivos. Finalmente, um processo aberto de decisão foi designado para criar progresso tecnológico, fazendo uma lista de usuários e produtores numa comunidade global que operaria fora dos canais tradicionais de governos e empresas.

Quatro normas surgiram, para a implementação desses princípios, e eram consistentes com regras formais e expectativas da comunidade de especialistas. A primeira delas consistiu na introdução da competição na provisão da infraestrutura da rede e serviços, promovendo à interligação em 
rede digital mais eficiente e inovadora. A segunda norma foi a de limitar intrusão por governos e certos interesses corporativos em gerenciar a criação e administração de recursos de infraestrutura virtuais, como os números da internet e nomes ou padrões da internet. A terceira norma se caracterizou por abranger padrões abertos que não criam vantagens de propriedade tecnológica dos recursos de infraestrutura virtual. A quarta norma consistiu em tomar medidas positivas para estender acesso universal a serviços da internet e informação, sem necessariamente replicar os modelos universais tradicionais de serviços das telecomunicações.

Os autores apontam que a governança da internet é mais que um experimento com tecnologia, pois desde o início assumiu a possibilidade de convergência entre aplicações e objetivou esse desenvolvimento. Dessa forma, modularidade e competição foram consideradas partes da infraestrutura de TIC. Em suma, a comunidade da internet estabeleceu sua coesão e processos de trabalho únicos por causa da sua incubação como um projeto de pesquisa patrocinado pelo governo. Essa origem significa que nenhuma preferência estratégica de companhias dominou o manuseio dos direitos de propriedade intelectual para a internet.

O livro destaca o surgimento de duas instituições que refletem a nova governança da internet: a Internet Engineering Task Force (IETF), como o veículo primário utilizado para coordenar a tarefa de estabelecer padrões para o software que permite interligar redes; e, o Internet Corporation for Assigned Names and Numbers, ICANN, que opera como um sistema não governamental de especialistas, com um processo aberto a todos partícipes. Em face de questões como a dependência de estruturas hierárquicas para suas operações e escassez de recursos, houve a centralização de alguns aspectos e a necessidade de delegação do controle da internet.

Cowhey e Aronson constatam que a história da internet é uma história de sucesso tecnológico. Ela transformou a maneira como o mundo se comunica e como se utiliza da informação para servir a sociedade. E mais, o ICANN e IETF não são instituições perfeitas, mas fornecem exatamente o tipo de inovação que deve se esperar no ponto de inflexão, pois são experimentos da governança global.

No sumário e conclusões com Donald Abelson, os autores oferecem um desenho preliminar para futuras políticas de governança de TIC. Não obstante seja uma mudança que começa nos mercados domésticos, o desafio Revista de Direito, Estado e Telecomunicações, v. 2, n. 1, p. 197-212 (2010) 
é global e a regulação em base nacional é impraticável. As escolhas políticas nacionais têm um componente inevitavelmente internacional.

A análise é resumida em cinco guias para novas políticas: a) primeiro, no ponto de inflexão há mais pressão sobre as estruturas de preços no sentido de descartar negócios da antiga economia política como subsídio cruzado em preços de serviços, por causa da fragmentação de metas entre indústrias de software e hardware; b) segundo, políticas vencedoras se baseiam cada vez mais em intervenções que buscam atuar com precisão, de forma mais estreita, para identificar denominadores comuns; c) terceiro, a abordagem norte-americana facilita a entrada de redes, fornecedores e aplicações para não dificultar a interoperabilidade (modularidade); d) quarto, existe apoio político potencial para empreendedores que facilitarem novos rendimentos de inovação ou novas classes de serviços interligados em rede; e) quinto, a sofisticação das redes de TIC criou uma nova gama de questões que envolvem privacidade, direito de conteúdo e controle de dados.

À luz desses guias da economia política, os autores propõem quatro princípios básicos. Depois, tratam de dez normas que implementam os princípios de modo a começar a imaginar como inovações podem transformar princípios em realidades do mercado.

A primeira norma se refere a um design institucional e enfatiza a escolha de agentes flexíveis. ${ }^{12}$

As normas 2 e 3 tratam da permissibilidade da cadeia de fornecimento modular, no sentido de conferir mais competitividade e potencial aceleração da modularidade. A norma 2 se refere à criação de capacidades virtuais comuns para a internet e competição neutra. A norma 3 visa reforçar a ideia de competitividade na cadeia de fornecimento.

A quarta norma enfatiza a importância da construção de redes ubíquas, de banda larga, competitivas, usando um toque regulatório 'leve' com

\footnotetext{
${ }^{12}$ Quatro guias para implementar a norma número 1: (1) Repousar em liderança privada e sem fins lucrativos sempre que possível, porque fóruns intergovernamentais são menos flexíveis e mais lentos. Ter regra não discriminatória para membros de organizações não governamentais que estabelecem regras que influenciam mercados. Qualificações devem ser razoáveis. Tomada de decisões transparentes e públicas é um elemento essencial.
} 
relação a preços, investimentos, e aspectos cruciais para prover serviços e redes de TIC.

A quinta norma reforça a política de competição da rede. O ponto de inflexão diminui o risco de força anticompetitiva, promove inovação ativa e pressiona os preços. Há três corolários que se referem a aspectos específicos.

O corolário 5.1 traduz-se na assertiva de que "Deixe a interconexão para o mercado quando não há prestador individual ou coletivo dominante". $\mathrm{O}$ estudo aponta que o unbundling não é mais desejável porque a competição de infraestrutura está se tornando um lugar comum.

O Corolário 5.2 pode ser expresso como "Adote um alcance mais restrito para regras destinadas a assegurar neutralidade da rede". Para explicar esse corolário, os autores fazem remissão ao Princípio do Annenberg Center ${ }^{13}$, discutido em uma reunião privada com uma variedade de partícipes.

Corolário 5.3: "Separe decisões sobre peering das decisões sobre interconexão quando lidar com a prestação de funções de valor adicionado da rede".

As normas 6 a 10 se dirigem aos consumidores de serviços. O ponto de inflexão indica que haverá avanços para permitir serviços convergentes, com mais competição e com maior potencial de inovação. O papel do governo é o de permitir a experimentação de novas aplicações, pensar em

\footnotetext{
${ }^{13}$ No âmbito do Annenberg Institute, sugerem-se cinco princípios: 1.Operadores e consumidores devem ganhar. 2.Utilize regulação light touch quando há significante poder do mercado. A ênfase regulatória deve ser em princípios gerais de política de competição, não em condutas detalhadas nos mercados de telecomunicações. 3.Garanta acesso básico da banda larga. Operadores de redes banda larga podem evitar regulação intrusiva, fornecendo ' banda larga básica de acesso', um serviço de conectividade básico a internet. Além desse nível, operadores deveriam determinar livremente os parâmetros dos serviços, incluindo performance, preço, e a priorização de tráfico. 4. Usuários devem ter liberdade de escolha de terminais e aplicações de software. A liberdade de terminal deve se aplicar desde que não prejudique a rede, seja ela wireless, móvel, nomádica, híbrida. A segunda liberdade é mais difícil, pois envolve serviços para gerenciar serviços aceitáveis. 5. Oferecer transparência. Consumidores devem receber termos e condições claros dos serviços, inclusive como o operador da rede - o provedor de serviços da internet - usará a informação pessoal dos usuários e como controlará o conteúdo disponível a eles.
} 
regras para globalização de conteúdo de multimídia, visar a um sistema mais flexível de direitos de propriedade, melhorar os direitos de propriedade para dados pessoais e na implementação de serviços em que os usuários levem suas informações com eles, quando saírem de aplicações.

Constata-se, portanto, que os autores são a favor de uma agenda política agressiva que se baseie nos princípios e normas propostas nesse capítulo.

Assim, não obstante a obra aponte tendências políticas para lidar com o novo contexto nos mercados globais de TICs, ela não estabelece o cálculo exato para a resolução da equação que envolve mercados dominados pela inovação de serviços e tecnologias, definição de diretrizes políticas e ação regulatória. O que o livro aponta é que as possíveis fórmulas existentes possuem fatores-chave, sem os quais as mudanças não ocorrerão nas direções desejáveis. Qualquer que seja o resultado buscado, a evolução das redes de Tecnologia da Informação e Comunicação é a variável central a ser considerada. 
